\title{
Investigating the longitudinal interrelationship between housework time and market earnings: disentangling between-person from within-person effects
}

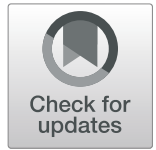

Meng Sha Luo ${ }^{1 *}$ and Ernest Chui ${ }^{2}$

\footnotetext{
* Correspondence: mengshal@zju. edu.cn

'Department of Sociology, Zhejiang University, 866 Yuhangtang Road, Hangzhou, Zhejiang, China Full list of author information is available at the end of the article
}

\begin{abstract}
The work-to-family hypothesis and the family-to-work hypothesis provide alternate explanations for the housework-earnings relationship. This study examines these competing theoretical perspectives and explores the longitudinal, cross-lagged relationship between housework time and market earnings. The data consist of five waves (2004-2015) of an ongoing open cohort study with 1827 married Chinese adults living in urban China. The random intercept cross-lagged panel model, which can separate stable, between-person differences from within-person processes, was applied. Overall, this study found that the bidirectional housework-earnings relationship mainly occurred at the between-person level: higher market earnings were related to less housework time. Few relationship was observed at the withinperson level: over the 12-year investigation period from 2004 to 2015, women's (but not men's) within-person fluctuations in market earnings influenced their housework time 2 years later only from 2004 to 2006. Overall, this study partially lends support to the work-to-family hypothesis but fails to show evidence for the family-to-work hypothesis.
\end{abstract}

Keywords: Doing gender, Division of labor, Gender equality, Work-family conflict

\section{Introduction}

The socialist egalitarian gender discourses encouraged women to cross the boundaries and challenge the separate spheres model to the extent that double burdens became a heated topic both within women themselves and among the state sectors (Luo 2019). Under Mao's leadership, working Chinese women were publicized as the socialist ideal, and the state provided some basic social welfare and services, which were said to have the potential to shift women's private responsibilities into public responsibilities (Zhang and Hannum 2015).

Since the reform and opening-up, a strand of research, observing the declining state protection, has underscored the diminishing role of the state in promoting gender equality (Bian 2002; Ji et al. 2017; Pimentel 2006; Zuo 2003, 2014; Zuo and Bian 2001).

(c) The Author(s). 2020 Open Access This article is licensed under a Creative Commons Attribution 4.0 International License, which permits use, sharing, adaptation, distribution and reproduction in any medium or format, as long as you give appropriate credit to the original author(s) and the source, provide a link to the Creative Commons licence, and indicate if changes were made. The images or other third party material in this article are included in the article's Creative Commons licence, unless indicated otherwise in a credit line to the material. If material is not included in the article's Creative Commons licence and your intended use is not permitted by statutory regulation or exceeds the permitted use, you will need to obtain permission directly from the copyright holder. To view a copy of this licence, visit http://creativecommons.org/licenses/by/4.0/. 
Its basic idea is that in the reform era, the role of the urban employers and the government advocate of women's rights has diminished, as reflected by important indicators in the labor market (e.g., labor force participation rate, income, occupational segregation, and mobility processes). How do women in the reform era integrate market work and domestic work? How does market work affect domestic work, and vice visa? Does the relationship between domestic work and market work vary by gender?

To date, empirical studies that document the causal relationships between housework time and market earnings are limited (Carlson and Lynch 2017). Such a problem is even more prominent in China's context, where there is a near absence of similar studies investigating the order of effects between housework time and market earnings. Attempting to address these questions and fill the gap in the literature, this study makes use of a 12-year-long survey. It employs the random intercept cross-lagged panel model to identify whether there is a reciprocal relationship between housework time and market earnings or simply a unidirectional relationship among married adults living in the early twenty-first century in urban China. If a bidirectional relationship exists, it further examines which of the two effects is stronger. Additionally, it tests the moderating role of gender by using multiple group analyses.

\section{Work and family changes in China since the reform and opening-up}

From 1978 onward, a series of reforms unfolded in China, with the economic reform being the center. Underlying the market-oriented reform was a shift of ideology. Dramatic economic reform, de-collectivization of the communal system, and other great changes all saw a significant devolution of responsibility borne by the government. The social transformation exerted a great influence on gender relations. We summarize the major changes in both domestic work and paid work in this era.

In terms of domestic work, absolute housework time decreased. The Survey on the Social Status of Women in China is co-organized by All-China Democratic Women's Federation, National Statistics Bureau, and Women's Studies Institute of China. The survey was conducted every 10 years and finished the first, second, and third waves in 1990, 2000, and 2010. The sample participants were Chinese adults aged 18-64. The report reveals that from 1990 to 2000, women's housework time (including cooking, laundry, and other tasks) decreased, although slightly, from 225 min per day to 215 min, while men's housework time decreased from $106 \mathrm{~min}$ to $86 \mathrm{~min}$ (National Bureau of Statistics 2004). These figures seem to suggest that men are appropriating more benefits of the reduced housework brought by advanced technologies than women are.

In terms of paid work, prior studies show that in the early reform era (in the late 1980s), urban Chinese women earned between 80 and $90 \%$ as much as men did, which was at the top of the range of the differential in Asia (between 51 to 75\%) (Tang and Parish 2000). However, gender wage differentials expanded with further reform. Empirical research reveals that although the gender-based occupational segregation existed before the restructuring of state-owned enterprise (SOE) (Liu 2007), the earnings of urban working-age women still exceeded $80 \%$ of men's earnings, indicating a relatively small gender wage gap (Gustafsson and Li 2000). Bian and Logan (1996) found that gender wage differentials changed little from 1978 to 1993, with a $15.2 \%$ male advantage in 1978 and an $18.3 \%$ male advantage in 1993. Another study found that 
occupational segregation was one of the major determinants of gender wage differentials, especially in SOEs (Wu and Wu 2009).

There was also a new valorization of Confucianism and a re-feminization of female images, pushing women to return to their traditional roles. The national survey reveals a revival of traditional values concerning the division of labor among modern Chinese families. The Survey on the Social Status of Women in China reveals that from 2000 to 2010 , there was a steady increase in the rate of women's recognition that "men should be in charge of the external affairs and women domestic affairs" (50.4\% in 2000 and $54.8 \%$ in 2010) and that "a good marriage is better than a good job for a woman" (37.3\% in 2000 and $48.0 \%$ in 2010) (National Bureau of Statistics 2012). Moreover, men's support for the traditional ideology with regard to the separate spheres model increased from 51.8\% in 1990 to $53.9 \%$ in 2000 and 61.6\% in 2010 (National Bureau of Statistics 2004, 2012).

To our knowledge, no existing studies have examined the longitudinal relationship between domestic work and paid work among Chinese adults by examining the dynamic interrelationship between housework time and market earnings. The present study contributes to the housework-earnings relationship literature by filling these gaps. Given that few studies on Chinese adults have documented the interrelationship between housework time and market earnings, below, we review the specific studies on the housework-earnings relationship, most of which are based on Western individuals.

\section{Theoretical hypotheses}

Although only a few prior studies have examined the longitudinal associations between housework time and market earnings, several competing theories suggest two possibilities regarding the housework-earnings relationship. While some studies present a "work-to-family" hypothesis, indicating that market work performance affects the allocation of time spent on domestic work, other studies present a "family-to-work" hypothesis, indicating that time spent on domestic work affects individual market earnings (Carlson and Lynch 2017). The work-to-family hypothesis, supported by the time availability perspective, the relative resources perspective, the gender perspective, and the autonomy theory, emphasizes the potential effect of market performance on housework time. The family-to-work hypothesis, supported by human capital theory, emphasizes the detrimental effect of domestic labor on market labor. We elaborate on each of the theoretical perspectives below.

\section{Unidirectionality: work-to-family hypothesis}

Family scholars have proposed several well-known theories in explaining men's and women's dissimilar allocations of time to unpaid domestic work. Growing extensively since the 1970s, several perspectives on the division of household labor dominate: the time availability perspective, the relative resources perspective, the gender perspective, and autonomy theory (Bianchi and Milkie 2010; Bianchi et al. 2000; Fahlén 2016; Lachance-Grzela and Bouchard 2010; Sayer 2005; Shelton and John 1996). All these perspectives imply a work-to-family hypothesis, with the latter three directly indicating a causal relationship that higher market earnings lead to less housework time. 
The time availability perspective characterizes the division of household labor as the result of women's and men's other time commitments (Hook 2010 Hook 2017; Shelton and John 1996). It assumes that couples divide household tasks according to the time they each have available (Lachance-Grzela and Bouchard 2010). The relative resources account (also referred to as economic dependence, economic exchange, or the bargaining explanation) assumes that the person who is to carry out household tasks is chosen through a process of bargaining, with those who have more resources doing less housework as an exchange (Pinto and Coltrane 2009).

The above two perspectives share the assumption that housework is less pleasing, to the extent that both spouses are motivated to avoid or at least decrease their housework. These two perspectives fail to explain why women who have paid work time and resources comparable to those of their husbands still do most of the domestic work. The gender perspective is raised due to the limitations of the above two perspectives and has two main types. The first type is related to the gender display hypothesis, which interprets economically disadvantaged men who do less housework as "doing gender." (Brines 1994) found that if a husband earned much less than his wife, he would do considerably less housework to maintain his masculinity in the home. Another type is the gender neutralization hypothesis, which reveals that not only do economically dependent men do "gender" (by doing less housework), but breadwinner women also do gender (by doing more housework) (Greenstein 2000). Both types share the assumption that housework is a performance that can be used to neutralize the gender "deviance" in paid work. These two gender hypotheses are cited as evidence that gender overrides the power of money (Sullivan 2011) and is supported by national surveys (e.g., British Social Attitudes Survey, Panel Study of Income Dynamics).

Recently, studies find that the gender perspective is a "statistical fact" and is thus questionable. Concerning men's "doing gender" hypothesis, recent studies have shown that it only applies to a small, disadvantaged group of men; concerning women's "doing gender" hypothesis, previous studies fail to take women's absolute income into account (Sullivan 2011). Bringing women's absolute level of market earnings into account, the initial relationship where breadwinner women who earn more than their husbands do more housework to compensate for their "unfeminine" roles in the labor market disappears. This finding leads scholars to repudiate the relative resources perspective and the gender perspective and propose an alternative perspective: autonomy theory (Gupta 2006, 2007; Gupta and Ash 2008). Autonomy theory suggests an overall negative relationship between housework time and market earnings: women's higher levels of absolute earnings imply that they have less housework time, irrespective of their husbands' earnings and the proportion of the couples' total earnings they contribute (i.e., women's relative earnings). This theory claims that "her money, her time" better explains women's housework-earnings relationship than the relative resources theory and the gender perspective (Gupta 2006).

\section{Unidirectionality: family-to-work hypothesis}

In contrast to the literature that highlights the potential bargaining power brought by paid work and thus the possible beneficial effect of less housework, another strand of literature emphasizes the negative effects of domestic work on the paid work. The human capital theory is 
often cited as evidence for this strand of literature. According to human capital theory, market earnings are the product of investments in specialized human capital. As such, women's greater allocation of time to household tasks, such as childcare and housework, means less time for human capital investment and lower market earnings (Becker 1985). Nonetheless, although the human capital framework suggests a wage penalty for women, the empirical results are mixed. Some studies find that married women suffer wage penalties after getting married and becoming mothers (Zhang et al. 2008), while other studies find that married women do not suffer such penalties when living with their parents (Yu and Xie 2018). Additionally, previous studies suggest that when looking beyond the pure wage differentials and considering the non-wage compensation (i.e., the fringe benefits), the gender gap in earnings narrows substantially (Altonji and Blank 1999).

\section{Bidirectionality: the moderating role of gender}

Both the work-to-family hypothesis and the family-to-work hypothesis assume a unidirectional relationship between housework time and market earnings. Both hypotheses ignore the gender element. In other words, past research documenting the association between housework time and market earnings suffers from limitations of "the use of cross-sectional data and single direction, single-equation models" (Carlson and Lynch 2017: 201). Taking gender into account, a third perspective points out the existence of a bidirectional relationship between the two. Analyzing two waves of the National Survey of Families and Households (NSFH 1987-1988 and 1992-1994), Carlson and Lynch (2017) recently found that for husbands, there was only a family-to-work relationship. For wives, there was a reciprocal housework-earnings relationship, with the work-to-family relationship being stronger than the family-to-work relationship.

Despite its merits, the study of Carlson and Lynch has several limitations. First, although their study analyzed longitudinal data to establish relational directionality between housework time and market earnings, their study only involved two waves of data. It did not control for stable, between-person differences. This might be problematic given that findings obtained from analyzing two waves of data cannot inform us whether these developmental processes of the housework-earnings relationship remain stable over time. Nor does it tell us whether such within-person processes remain after controlling for the stable, between-person differences through the inclusion of random intercepts. Distinguishing the within-person level of housework-earnings relationship from the between-person level requires more waves of data. Second, their study used older data that were collected in the late 1980s and early 1990s. Given that great social changes have taken place in both the workplace and the family sphere in the past two decades, more recent data are needed. Third, their findings may not apply to China, where socialist egalitarian discourses still influence people's daily lives. Therefore, this study aims to use more recent data with more measurement occasions and an up-to-date analytic method to identify the longitudinal relationship between housework time and market earnings among married adults in urban China.

\section{Method}

Sample

Data are drawn from the China Health and Nutrition Survey (CHNS), which is coconducted by the Carolina Population Center, the University of North Carolina at 
Chapel Hill, and the National Institute of Nutrition and Food Safety in China. The survey collects multilevel data from individuals, households, and their communities. The goal is to understand how the economic, demographic, and social transformation of China affects a wide array of health-related outcomes. The CHNS began in 1989 and has published ten waves of data to date. We include five waves of CHNS data collected in 2004, 2006, 2009, 2011, and 2015.

This study focuses on married individuals, given that the major theories explaining the housework-earnings relationship are mainly restricted to married individuals (Bianchi et al. 2000). Additionally, we only study respondents who have urban hukou (household registration status) due to the complexity of the rural labor market. We do not limit the sample to those who have a paid job and those who spend time doing housework. For those who answer "no" to housework questions, their housework time is replaced with 0 . For those who are not at work in the survey year, their market earnings are replaced with 0 . Housework time and market earnings are standardized. Furthermore, respondents are limited to those who appear at least three times, as required by the analytic methods. We also restrict the sample to respondents who were 18 to 60 years old in all waves. The final sample consists of 1827 respondents with a total of 6028 observations. The average attendance is 3.30 times.

\section{Measures}

Key variables of interest are housework time and market earnings. The CHNS collected information on four core types of household activity: buying food for the household, preparing and cooking food, washing and ironing clothes, and cleaning the house. For every kind of activity, the respondent was asked the next question, "How much time did you spend on this per day, on average? (minutes)." A new housework time variable was generated to denote the overall amount of time in minutes per day each individual had spent on unpaid domestic work by adding up all scores under each type of housework. Market earnings were calculated as annual earnings from the primary job, including annual wage income, bonuses, and in-kind income. We choose to use annual earnings instead of hourly wages because, in China, employees are usually paid by month. Annual earnings were inflated to 2015 RMB currency values.

We include a series of control variables that were previously identified as covariates with both housework time and market earnings. These covariates involve individual sociodemographic information, job characteristics, family background, and regional characteristics.

Individual sociodemographic characteristics include gender and education. Gender is coded 1 for female and 0 for male. Prior research indicates that Chinese women with higher education report less housework than women with lower education. Education is also recognized as one of the key factors in closing the gender pay gaps (Altonji and Blank 1999). Education is a continuous variable indicating the actual years of schooling the respondent had completed.

Job characteristics are captured by three variables: daily paid work hours, work sector, and occupation. Daily paid work hours were measured as the average hours worked per day. Prior research has found that women's housework time is negatively associated with their market work hours but positively associated with husbands' market work 
hours (Chen and Ge 2018). The work sector is categorized into three groups: the market sector, the state sector, and the collective sector. The work sector is taken into account because the work sector traditionally is an all-encompassing welfare institution (Wang 2003), and people's average work hours differ significantly across work sectors (Wu et al. 2016). The collective sector is added because prior research reveals that in the socialist economy, men were concentrated in the state sector, while women were concentrated in the collective sector (Bian 2002). Occupation is a categorical variable with five groups: manual worker, service worker, office clerk, professional or technician, and administrator, executive, or manager. Occupation is controlled for because prior research has found a higher explanatory power of the gender pay gap by job characteristics (e.g., occupation) than by human capital (e.g., education and seniority) (Altonji and Blank 1999).

Family background is taken into account, including parental status and family wealth, given that prior research has suggested strong correlations between family structure and both domestic work and paid work. Parental status indicates whether the respondents were taking care of children under age six (coded as 1 ) or not (coded as 0 ). Previous research has revealed that transitioning to parental status increases the gap between mothers and fathers in housework (Hook 2017) and involves a wage premium for fathers and a wage penalty for mothers (Zhang and Hannum 2015). Family wealth was measured in the continuous form and calculated as the total income earned by all adults living in the household, which was inflated to 2015 RMB currency values.

Regional characteristics capture the degrees of marketization and all other differences. Prior studies have revealed the associations between the degrees of marketization and housework time (Luo and Chui 2019) and market earnings (Bian and Logan 1996; $\mathrm{He}$ and $\mathrm{Wu}$ 2018). The marketization index is an oft-cited factor used to examine provincial variations in terms of the level of provincial economic development (Fan et al. 2011). It is a summary score of five aspects with 18 basic dimensions that involve the relationship between the government and market, the development of non-state-owned enterprises, the development level of the product market, the development level of the resource market, and the development level and the legal environment (Wang et al. 2017). We also controlled for other regional differences by including four region dummy variables: coastal region, northeast region, inland region, and mountainous southern region.

\section{Statistical analyses}

Traditionally, the cross-lagged panel model (CLPM) has been regarded as a typical approach to studying causal influences between two (or more) variables in longitudinal panel data. Recent research shows that by including autoregressive parameters, the CLPM only accounts for the temporal stabilities of the variables and fails to account for time-invariant, trait-like stable individual differences adequately. That is, the estimates of lagged parameters are confounded by the relationship that exists at the between-person level. As a result, estimates may be biased (Mund and Nestler 2018).

To address this issue, recent studies have proposed an alternative approach-the random intercepts cross-lagged panel model (RI-CLPM). The RI-CLPM employs a multilevel perspective and distinguishes the within-person process (i.e., capturing associations on the individual's own level) from stable, between-person differences (i.e., 
capturing associations in rank order positions of individuals). It allows the separation of within-person effects from between-person effects. By including a random intercept (i.e., a factor with all loadings constrained to 1), the RI-CLPM accounts for trait-like, time-invariant stability and thus partials out between-person variance and obtains the real within-person dynamics (Hamaker et al. 2015).

Figure 1 shows an illustration of the RI-CLPM examined in the current study. The random intercepts reflect an individual's average, stable level of housework time and market earnings. The autoregressive parameters $\alpha 2-\alpha 5$ and $\delta 2-\delta 5$ relate to the degree of within-person carry-over effects, thus showing whether deviations from one's own expected market earnings or housework time score at one measurement occasion carry over to the next occasion. The cross-lagged parameters $\beta 2-\beta 5$ and $\gamma 2-\gamma 5$ refer to relationships at the within-person level and can be interpreted as the extent to which changes in an individual's deviations from the expected score of one variable (e.g., housework time) are predicted by deviations from the expected score of another variable (e.g., market earnings) at the previous measurement occasion after adjusting for the carry-over effects.

Structural equation modeling with Mplus 8.1 is used to estimate the models (Muthén and Muthén 1998-2017). Model fit is evaluated on the basis of local and global fit indices, including the chi-square, the comparative fit index (CFI), the root mean square error of approximation (RMSEA), and the standardized root mean square residual (SRMR). The commonly used criteria of a relatively good fit between the hypothesized model and the observed data are CFI values greater than or equal to 0.95, SRMR values less than or equal to 0.08, and RMSEA values less than or equal to 0.06 ( $\mathrm{Hu}$ and Bentler 1999).

The analyses consist of four steps. First, we estimate the CLPM (M1) of the longitudinal relationships between housework time and market earnings without covariates for

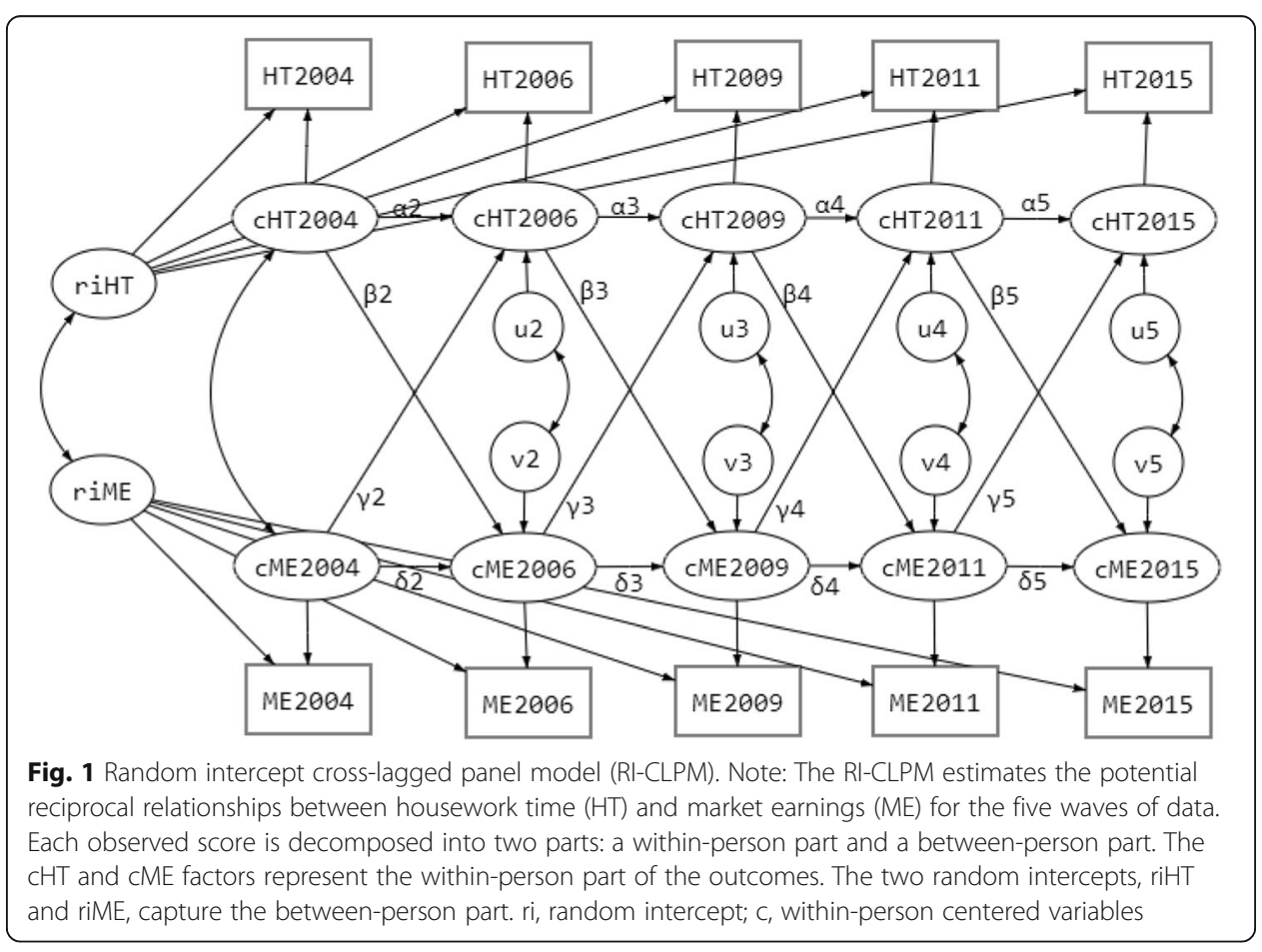


comparison reasons. Next, we estimate the RI-CLPM of the longitudinal relationships between housework time and market earnings without covariates (M2). We compare estimates of Model 1 and Model 2. Third, we estimate the RI-CLPM with covariates (M3). Finally, gender is examined as a moderator in the subsequent analysis; this is done by running the multiple group analyses with covariates included in the RI-CLPMs (M4). All continuous variables are standardized (except when reporting the descriptive results), and only baseline information of the covariates is used.

\section{Results}

\section{Descriptive results}

Table 1 reports descriptive statistics. On average, at each measurement occasion, female respondents reported a higher level of housework time and a lower level of market earnings than male respondents. From 2004 to 2015, for both men and women, housework time decreased, and market earnings increased.

Table 2 reports Pearson's correlations among the key variables. At nearly all measurement occasions, housework time was negatively associated with market earnings $\left(r_{\mathrm{s}}=-\right.$ 0.14 to -0.25$)$. More housework time in prior waves implied more housework time in later waves $\left(r_{\mathrm{s}}=0.28-0.55\right)$, and higher market earnings in prior waves also implied higher earnings in later waves $\left(r_{\mathrm{s}}=0.23-0.57\right)$.

\section{Results of the cross-lagged panel model}

The literature on the differences between CLPM and RI-CLPM suggests that we should not equate between-person effects with within-person effects. Thus, it is essential to control for the stable, between-person differences when examining the houseworkearnings relationship at the within-person level. Table 3 reports the fit indices of all models tested in this study. Table 4 reports estimates of the longitudinal relationships between market earnings and housework time based on the CLPM (M1), RI-CLPM without covariates (M2), and RI-CLPM with covariates (M3). For each of the models, we report their standardized estimates, standard errors, and $p$ values.

A standard CLPM is first estimated. The fit of the CLPM is rather poor: $\chi^{2}(24)=362$, CFI $=0.86$, RMSEA $=0.09$, and SRMR $=0.10$ (as shown in the first row of Table 3). Regarding the longitudinal housework-earnings relationship at the between-person level, the cross-lagged parameters show that in the 12year-long period, there was a long-lasting, reciprocal relationship between the two: higher market earnings at the prior measurement occasion implied less housework time at the next measurement occasion, and more housework time at the prior measurement occasion implied lower market earnings at the next measurement occasion. The dominance of the two causal effects was mixed, however. At some measurement occasions, the housework's causal effect was larger; at other measurement occasions, earnings' causal effect was larger. The autoregressive parameters reveal strong carry-over effects; that is, higher earnings in early waves predicted higher earnings in the future, and longer housework time in early waves predicted longer housework time in the future as well. Across all measurement occasions, the carry-over effects were larger than the cross-lagged effects. 
Table 1 Descriptive results

\begin{tabular}{|c|c|c|c|c|c|}
\hline & \multicolumn{2}{|l|}{ Mean/\% } & \multicolumn{3}{|l|}{ SD } \\
\hline Female & \multicolumn{2}{|l|}{57} & \multicolumn{3}{|l|}{0.49} \\
\hline Age & \multicolumn{2}{|l|}{42.11} & \multicolumn{3}{|l|}{7.8} \\
\hline Daily paid work hours & \multicolumn{2}{|l|}{5.32} & \multicolumn{3}{|l|}{4.01} \\
\hline \multicolumn{6}{|l|}{ Occupation } \\
\hline Manual worker & \multicolumn{2}{|l|}{24} & \multicolumn{3}{|l|}{0.43} \\
\hline Service worker & \multicolumn{2}{|l|}{25} & \multicolumn{3}{|l|}{0.43} \\
\hline Office clerk & \multicolumn{2}{|l|}{14} & \multicolumn{3}{|l|}{0.34} \\
\hline Professional/technician & \multicolumn{2}{|l|}{26} & \multicolumn{3}{|l|}{0.44} \\
\hline Administrator/executive/manager & \multicolumn{2}{|l|}{11} & \multicolumn{3}{|l|}{0.31} \\
\hline \multicolumn{6}{|l|}{ Work sector } \\
\hline Market sector & \multicolumn{2}{|l|}{38} & \multicolumn{3}{|l|}{0.49} \\
\hline Collective sector & \multicolumn{2}{|l|}{11} & \multicolumn{3}{|l|}{0.32} \\
\hline State sector & \multicolumn{2}{|l|}{51} & \multicolumn{3}{|l|}{0.5} \\
\hline Schooling years & \multicolumn{2}{|l|}{10.21} & \multicolumn{3}{|l|}{3.02} \\
\hline Parental status & \multicolumn{2}{|l|}{0.11} & \multicolumn{3}{|l|}{0.32} \\
\hline Marketization score & 6.06 & & 1.02 & & \\
\hline Region & & & & & \\
\hline Coastal & 28 & & 0.45 & & \\
\hline Northeast & 24 & & 0.43 & & \\
\hline Inland & 31 & & 0.46 & & \\
\hline Southern & 17 & & 0.37 & & \\
\hline Family wealth & 44,021 & & 38,396 & & \\
\hline & Longitud & ousewo & (minutes & lay) by w & \\
\hline & 2004 & 2006 & 2009 & 2011 & 2015 \\
\hline Whole sample & 142 & 137 & 114 & 115 & 104 \\
\hline Men & 81 & 75 & 50 & 50 & 54 \\
\hline Women & 173 & 168 & 173 & 173 & 152 \\
\hline & Longitud & nnual $m$ & arnings b & & \\
\hline & 2004 & 2006 & 2009 & 2011 & 2015 \\
\hline Whole sample & 8,480 & 9,495 & 15,194 & 17,842 & 24,604 \\
\hline Men & 12,217 & 13,718 & 20,393 & 22,857 & 32,198 \\
\hline Women & 6,614 & 7,381 & 10,445 & 13,379 & 17,497 \\
\hline
\end{tabular}

\section{Results of the random intercept cross-lagged panel model}

Model 2 examines the autoregressive and cross-lagged effects between housework time and market earnings at the within-person level without any covariates. This model separates the trait-like stability from moment-to-moment stability. It shows appropriate model fit: $\chi^{2}(21)=115$, CFI $=0.96$, RMSEA $=0.05$, and SRMR $=0.05$. Although conservative, the results of the chi-square test support that the RI-CLPM fits better than the CLPM $\left(\Delta \chi^{2}(3)=247, p<0.001\right)$.

The standard estimates of the RI-CLPM (M2) reveal great differences from the estimates of the traditional CLPM (Table 4). The RI-CLPM reveals a more complex picture than the traditional CLPM does. We first notice that the estimates of the RI-CLPM are smaller than those of the CLPM. This was expected, given that the RI-CLPM separates 
Table 2 Correlations of housework time and market earnings

\begin{tabular}{|c|c|c|c|c|c|c|c|c|c|}
\hline & HT2004 & HT2006 & HT2009 & HT2011 & HT2015 & ME2004 & ME2006 & ME2009 & ME2011 \\
\hline HT2006 & $0.36^{* *}$ & & & & & & & & \\
\hline HT2009 & $0.41^{* *}$ & $0.46^{* *}$ & & & & & & & \\
\hline HT2011 & $0.31^{* *}$ & $0.41^{* *}$ & $0.55^{* *}$ & & & & & & \\
\hline HT2015 & $0.28^{* *}$ & $0.33^{* *}$ & $0.42^{* *}$ & $0.47^{* *}$ & & & & & \\
\hline ME2004 & $-0.15^{* *}$ & $-0.20^{* *}$ & $-0.13^{* *}$ & $-0.13^{* *}$ & -0.09 & & & & \\
\hline ME2006 & $-0.19^{* *}$ & $-0.25^{* *}$ & $-0.17^{* *}$ & $-0.13^{* *}$ & $-0.15^{* *}$ & $0.57^{* *}$ & & & \\
\hline ME2009 & $-0.23^{* *}$ & $-0.21^{* *}$ & $-0.21^{* *}$ & $-0.17^{* *}$ & $-0.16^{* *}$ & $0.44^{* *}$ & $0.49^{* *}$ & & \\
\hline ME2011 & $-0.12^{* *}$ & $-0.15^{* *}$ & $-0.16^{* *}$ & $-0.14^{* *}$ & $-0.15^{* *}$ & $0.24^{* *}$ & $0.42^{* *}$ & $0.38^{* *}$ & \\
\hline ME2015 & $-0.19^{* *}$ & $-0.19^{* *}$ & $-0.17^{* *}$ & $-0.16^{* *}$ & $-0.20^{* *}$ & $0.23^{* *}$ & $0.38^{* *}$ & $0.42^{* *}$ & $0.44^{* *}$ \\
\hline
\end{tabular}

Note: Cells report Pearson's correlation coefficients

Italicized data show within-wave correlations between market earnings and housework time $H T$ housework time, ME market earnings

${ }^{*} p<0.05$

$* * p<0.01$

within-person differences from the between-person differences. Regarding the earnings $\rightarrow$ housework effects, after adjusting for between-person differences, only market earnings in 2011 predicted less housework time in 2015 at the within-person level $(\gamma 5=-$ $0.09, \mathrm{SE}=0.04)$. Regarding the housework $\rightarrow$ earnings effects, only individuals' longer housework time in 2006 and 2009 predicted their lower market earnings in 2009 and $2011(\beta 3=-0.11, \beta 4=-0.08)$, respectively. The cross-lagged effects of housework time and market earnings on each other did not significantly differ. The autoregressive parameters also display slight differences from the estimates of CLPM: although most early housework time and market earnings still predicted future housework time and market earnings, individuals' housework time in 2004 did not predict their housework time in $2006(\alpha 2=-0.03, \mathrm{SE}=0.06)$, and individuals' market earnings in 2006 did not predict their earnings in $2009(\delta 3=-0.02, \mathrm{SE}=0.08)$.

We do not constrain the autoregressive and cross-lagged parameters to be equal across measurement occasions because the intervals are not equally spaced. In the following model, we add more covariates to check whether the found housework-earnings relationships were persistent. In Model 3 (M3), we include a series of control variables. Model 3 also displays appropriate model fit: $\chi^{2}(119)=299$, CFI $=0.96$, RMSEA $=0.03$, and SRMR $=0.03$. This model was also better than the traditional CLPM (M1).

Adding more covariates makes most of the standardized parameters smaller, suggesting that these covariates combined explained part of the autoregressive relationships and cross-lagged relationships. Specifically, M3 shows that adding more covariates

Table 3 Fit indices of models

\begin{tabular}{lllllll}
\hline Models & $d f$ & BIC & $x 2$ & CFI & RMSEA & SRMR \\
\hline M1. CLPM (no covariates) & 24 & 30,820 & 362 & 0.86 & 0.09 & 0.10 \\
M2. RI-CLPM (no covariates) & 21 & 30,596 & 115 & 0.96 & 0.05 & 0.05 \\
M3. Rl-CLPM (with covariates) & 119 & 61,332 & 299 & 0.96 & 0.03 & 0.03 \\
M4. Multiple group (with covariates) & 226 & 59,249 & 408 & 0.93 & 0.03 & 0.04 \\
\hline
\end{tabular}

Covariates include age, age squared, daily paid work hours, occupation, work sector, years of education, parenthood status, family wealth, provincial level of marketization index, and geographical region. All continuous variables were standardized

BIC Bayesian information criterion, CFI comparative fit index, RMSEA root mean square error of approximation, SRMR standardized root mean square residual 
Table 4 Standardized parameter estimates of the RI-CLPMs

\begin{tabular}{|c|c|c|c|c|c|c|c|c|c|c|c|c|c|}
\hline \multirow[b]{2}{*}{ Parameters } & \multicolumn{3}{|c|}{$\begin{array}{l}\text { CLPM } \\
\text { (M1, no covariates) }\end{array}$} & \multicolumn{3}{|c|}{$\begin{array}{l}\text { RI-CLPM } \\
\text { (M2, no covariates) }\end{array}$} & \multicolumn{3}{|c|}{$\begin{array}{l}\text { RI-CLPM } \\
\text { (M3, with covariates) }\end{array}$} & \multicolumn{2}{|l|}{$\begin{array}{l}\text { RI-CLPM } \\
\text { (M4, men) }\end{array}$} & \multicolumn{2}{|c|}{$\begin{array}{l}\text { RI-CLPM } \\
\text { (M4, women) }\end{array}$} \\
\hline & Estimate & SE & $p$ & Estimate & SE & $p$ & Estimate & SE & $p$ & Estimate & $p$ & Estimate & $p$ \\
\hline \multicolumn{14}{|c|}{ Autoregressive parameters } \\
\hline $\begin{array}{l}\text { HT2004 } \rightarrow \\
\text { HT2006 } \\
\text { (a2) }\end{array}$ & 0.38 & 0.03 & 0.00 & -0.03 & 0.06 & 0.62 & 0.05 & 0.05 & 0.25 & 0.06 & 0.49 & 0.00 & 0.98 \\
\hline $\begin{array}{l}\text { HT2006 } \rightarrow \\
\text { HT2009 } \\
\text { (a3) }\end{array}$ & 0.48 & 0.03 & 0.00 & 0.13 & 0.05 & 0.01 & 0.10 & 0.04 & 0.03 & -0.01 & 0.95 & 0.11 & 0.05 \\
\hline $\begin{array}{l}\text { HT2009 } \rightarrow \\
\text { HT2011 } \\
\text { (a4) }\end{array}$ & 0.54 & 0.02 & 0.00 & 0.30 & 0.03 & 0.00 & 0.18 & 0.04 & 0.00 & 0.17 & 0.00 & 0.15 & 0.00 \\
\hline $\begin{array}{l}\text { HT2011 } \rightarrow \\
\text { HT2015 } \\
\text { (a5) }\end{array}$ & 0.48 & 0.03 & 0.00 & 0.19 & 0.05 & 0.00 & 0.10 & 0.05 & 0.03 & 0.19 & 0.00 & 0.06 & 0.34 \\
\hline $\begin{array}{l}\text { ME2004 } \rightarrow \\
\text { ME2006 } \\
(\delta 2)\end{array}$ & 0.60 & 0.03 & 0.00 & -0.56 & 0.26 & 0.03 & 0.58 & 0.05 & 0.00 & 0.43 & 0.00 & 0.52 & 0.00 \\
\hline $\begin{array}{l}\text { ME2006 } \rightarrow \\
\text { ME2009 } \\
(\delta 3)\end{array}$ & 0.51 & 0.03 & 0.00 & -0.02 & 0.08 & 0.85 & 0.36 & 0.05 & 0.00 & 0.29 & 0.00 & 0.33 & 0.00 \\
\hline $\begin{array}{l}\text { ME2009 } \rightarrow \\
\text { ME2011 } \\
(\delta 4)\end{array}$ & 0.36 & 0.02 & 0.00 & 0.16 & 0.03 & 0.00 & 0.21 & 0.03 & 0.00 & 0.22 & 0.00 & 0.17 & 0.00 \\
\hline $\begin{array}{l}\text { ME2011 } \rightarrow \\
\text { ME2015 } \\
(\delta 5)\end{array}$ & 0.43 & 0.03 & 0.00 & 0.32 & 0.03 & 0.00 & 0.24 & 0.04 & 0.00 & 0.32 & 0.00 & 0.15 & 0.00 \\
\hline \multicolumn{14}{|c|}{ Cross-lagged parameters } \\
\hline $\begin{array}{l}\text { ME2004 } \rightarrow \\
\text { HT2006 } \\
(\gamma 2)\end{array}$ & -0.17 & 0.04 & 0.00 & -0.09 & 0.11 & 0.44 & -0.13 & 0.06 & 0.03 & 0.03 & 0.84 & -0.16 & 0.02 \\
\hline $\begin{array}{l}\text { ME2006 } \rightarrow \\
\text { HT2009 } \\
(\gamma 3)\end{array}$ & -0.05 & 0.03 & 0.09 & 0.02 & 0.05 & 0.67 & -0.03 & 0.04 & 0.45 & -0.03 & 0.68 & -0.08 & 0.18 \\
\hline $\begin{array}{l}\text { ME2009 } \rightarrow \\
\text { HT2011 } \\
(\gamma 4)\end{array}$ & -0.07 & 0.02 & 0.00 & -0.05 & 0.03 & 0.13 & -0.01 & 0.03 & 0.66 & -0.01 & 0.90 & -0.04 & 0.41 \\
\hline $\begin{array}{l}\text { ME2011 } \rightarrow \\
\text { HT2015 } \\
(\gamma 5)\end{array}$ & -0.09 & 0.03 & 0.00 & -0.09 & 0.04 & 0.03 & -0.04 & 0.04 & 0.37 & 0.01 & 0.88 & -0.06 & 0.29 \\
\hline $\begin{array}{l}\text { HT2004 } \rightarrow \\
\text { ME2006 } \\
(\beta 2)\end{array}$ & -0.10 & 0.03 & 0.00 & 0.18 & 0.12 & 0.12 & -0.01 & 0.03 & 0.72 & 0.04 & 0.61 & -0.04 & 0.37 \\
\hline $\begin{array}{l}\text { HT2006 } \rightarrow \\
\text { ME2009 } \\
(\beta 3)\end{array}$ & -0.10 & 0.03 & 0.00 & -0.11 & 0.06 & 0.04 & -0.03 & 0.04 & 0.42 & -0.01 & 0.84 & -0.07 & 0.14 \\
\hline $\begin{array}{l}\text { HT2009 } \rightarrow \\
\text { ME2011 } \\
(\beta 4)\end{array}$ & -0.10 & 0.03 & 0.00 & -0.08 & 0.03 & 0.01 & -0.05 & 0.03 & 0.11 & -0.07 & 0.16 & -0.04 & 0.32 \\
\hline $\begin{array}{l}\text { HT2011 } \rightarrow \\
\text { ME2015 } \\
(\beta 5)\end{array}$ & -0.11 & 0.03 & 0.00 & -0.04 & 0.04 & 0.32 & 0.07 & 0.05 & 0.18 & 0.10 & 0.18 & 0.05 & 0.42 \\
\hline
\end{tabular}

$H T$ housework time, ME market earnings 
could explain the three found relationships in Model 2: housework in $2006 \rightarrow$ earnings in $2009(\beta 3=-0.03, \mathrm{SE}=0.04)$, housework in $2009 \rightarrow$ earnings in $2011(\beta 4=-0.05$, $\mathrm{SE}=0.03)$, and earnings in $2011 \rightarrow$ housework in $2015(\gamma 5=-0.04, \mathrm{SE}=0.04)$, to the extent that these estimates become nonsignificant. Nonetheless, the earnings in 2004 $\rightarrow$ housework in 2006 relationship becomes significant $(\gamma 2=-0.13, \mathrm{SE}=0.06)$. This association suggests that individuals' deviations from expected housework time in 2006 were predicted by their market earnings in 2004. That is, individuals who had earnings higher than they typically would have earned were more likely to devote less time doing housework in 2006 than they typically would have done, after controlling for deviations from the expected housework time at the previous measurement occasion. The autoregressive effects are persistent, with one exception. Similar to Model 2, individuals' housework time in 2006 was still not predicted by their own housework time in 2004 $(\alpha 2=0.05, \mathrm{SE}=0.05)$. Other positive autoregressive effects suggest that within-person deviations from the expected housework time and market earnings predicted deviations from the expected housework time and market earnings at the next measurement occasion.

Overall, the RI-CLPM results suggest that from 2006 to 2015, at the within-person level, there were strong autoregressive effects of both housework time and market earnings but minimal cross-lagged effects between the two (with one exception). From 2004 to 2006, although earnings' autoregressive effect still existed, housework's autoregressive effect did not exist (in a statistical sense); perhaps, more importantly, the crosslagged effect only existed between 2004 and 2006 in the 12 years: higher than usual market earnings in 2004 predicted decreased housework time in 2006. Combined, these findings concerning the housework-earnings relationship from 2004 to 2006 lend support to the work-to-family hypothesis.

\section{Gender as a moderator}

Finally, as previous research has implied a moderating role of gender in the houseworkearnings relationship, in the fourth model, we divide the sample into two groups: female respondents $(n=2583)$ and male respondents $(n=3445)$. Then, we replicate Model 2 and Model 3 but run multiple group models in Mplus. Model 4 (M4) shows the results for both women and men. Standardized results are reported in Table 4.

The multiple group model shows appropriate model fit: $\chi^{2}(226)=408, \mathrm{CFI}=0.93$, RMSEA $=0.03$, and SRMR $=0.04$. The autoregressive parameters and the cross-lagged parameters display both similar and dissimilar effects between the two groups. The most evident similarity between men and women is that, for both genders, fluctuations in market earnings in all prior waves predicted positive changes in future market earnings. Nonetheless, there are some differences in terms of the strength of earnings' autoregressive effects. In the early 2 years, earnings' carry-over effects appeared to be larger for women than for men ( $\delta 2$ and $\delta 3)$, but such strengths disappeared in later years $(\delta 4$ and $\delta 5)$.

Another similarity is that, similar to the overall full model (M3), housework time in 2004 did not predict housework time in $2006(\alpha 2)$ for either gender. Despite this similarity, there are slight differences in housework's autoregressive effects between men and women: adjusting for socio-demographic characteristics and between-person 
differences, at the within-person level, men's housework time in 2006 did not predict their housework time in 2009, and women's housework time in 2011 did not predict their housework time in 2015.

Regarding the cross-lagged effects, men do not display cross-lagged effects, indicating that men's own housework time in early waves did not predict changes in their future market earnings and that men's market earnings in early waves did not predict changes in their future housework behavior. However, for women, although most cross-lagged effects are nonsignificant, the housework-earnings relationship was evident in 2004 and 2006; women's higher market earnings in 2004 predicted reduced housework time 2 years later. It was in 2004 and 2006 that the cross-lagged effect was larger than the housework's autoregression effect. Thus, it is now clear that the female group displays the cross-lagged effects. All these nuanced findings suggest the need to view the housework-earnings relationship not as a linear picture and to note gender differences in housework-earnings relationships.

Table 5 reports the associations between the covariates and the random intercepts of housework time. For both genders, the curvilinear trend of age on housework is not evident; however, when removing the age squared, age shows positive associations with housework time for both genders ( $B=0.10$ for men and $B=0.16$ for women), indicating that as people age, their housework time increases. Occupation, work sector, parental status, and family wealth do not show apparent associations with husbands' housework time. For husbands, shorter daily work hours, higher educational level,

Table 5 Standardized estimates of between-person differences in housework time and market earnings

\begin{tabular}{|c|c|c|c|c|c|c|c|c|}
\hline & \multicolumn{4}{|c|}{ DV: Housework time } & \multicolumn{4}{|c|}{ DV: Market earnings } \\
\hline & \multicolumn{2}{|l|}{$\overline{M e n}$} & \multicolumn{2}{|l|}{ Women } & \multicolumn{2}{|l|}{$\overline{M e n}$} & \multicolumn{2}{|l|}{ Women } \\
\hline & Estimate & $p$ & Estimate & $p$ & Estimate & $p$ & Estimate & $p$ \\
\hline Age & 0.04 & 0.95 & 0.85 & 0.12 & 1.39 & 0.04 & 0.76 & 0.20 \\
\hline $\mathrm{Age}^{2}$ & 0.36 & 0.58 & -0.44 & 0.42 & -1.64 & 0.01 & -1.16 & 0.05 \\
\hline Daily paid work hours & -0.16 & 0.04 & -0.11 & 0.13 & 0.68 & 0.00 & 0.25 & 0.01 \\
\hline \multicolumn{9}{|l|}{ Occupation (ref. = manual worker) } \\
\hline Service worker & -0.03 & 0.72 & 0.05 & 0.53 & -0.30 & 0.00 & -0.02 & 0.78 \\
\hline Office clerk & -0.03 & 0.73 & 0.08 & 0.34 & 0.08 & 0.28 & 0.00 & 0.96 \\
\hline Professional/technician & 0.02 & 0.88 & -0.14 & 0.14 & 0.20 & 0.02 & 0.42 & 0.00 \\
\hline Administrator/executive/manager & -0.04 & 0.65 & -0.04 & 0.56 & 0.14 & 0.07 & 0.06 & 0.39 \\
\hline \multicolumn{9}{|l|}{ Work sector (ref. $=$ market sector) } \\
\hline Collective sector & -0.08 & 0.31 & 0.18 & 0.03 & 0.01 & 0.84 & -0.06 & 0.42 \\
\hline State sector & 0.01 & 0.90 & 0.16 & 0.06 & 0.39 & 0.00 & 0.24 & 0.00 \\
\hline Schooling years & 0.18 & 0.03 & -0.17 & 0.01 & 0.19 & 0.02 & 0.26 & 0.00 \\
\hline Parental status & -0.07 & 0.32 & 0.05 & 0.43 & -0.04 & 0.54 & -0.03 & 0.69 \\
\hline Marketization score & 0.30 & 0.02 & -0.39 & 0.00 & 0.06 & 0.60 & -0.07 & 0.56 \\
\hline \multicolumn{9}{|l|}{ Region (ref. = coastal) } \\
\hline Northeast & 0.28 & 0.02 & -0.10 & 0.30 & -0.10 & 0.35 & -0.21 & 0.04 \\
\hline Inland & 0.29 & 0.03 & -0.28 & 0.01 & -0.05 & 0.71 & -0.34 & 0.00 \\
\hline Southern & 0.16 & 0.24 & -0.49 & 0.00 & -0.03 & 0.82 & -0.17 & 0.14 \\
\hline Family wealth & -0.14 & 0.08 & 0.05 & 0.47 & 0.22 & 0.00 & 0.14 & 0.04 \\
\hline
\end{tabular}


living in provinces with higher marketization level, and living in northeast and inland areas (instead of coastal areas) were all associated with more housework time. For wives, daily paid work hours, occupation, parental status, and family wealth were not associated with housework time. However, working in collective sectors (as opposed to working in market sectors) was associated with longer housework time, and higher educational level, living in provinces with higher marketization level, and living in inland and southern areas (instead of coastal areas) were associated with less housework time.

Table 5 also reports the associations between covariates and the random intercepts of market earnings. Both husbands and wives present curvilinear effects of age on market earnings: initially, earnings increased with age, and when reaching certain points, the pace of these increases slowed down. For both genders, longer market work hours, working as professionals/technicians (instead of working as manual workers), working in state sectors (as opposed to working in market sectors), and higher family wealth all had positive associations with market earnings. Although there was no evident regional difference in husbands' earnings, women living in the northeast, inland, and southern areas earned much less annually than women living in coastal areas.

\section{Conclusions and discussion}

The longitudinal association between housework and paid work is not clear. Prior research, including theoretical and quantitative studies, suggests a contrasting housework-earnings relationship. The time availability perspective, the relative resources theory, the gender perspective, and the autonomy theory all imply the work-tofamily hypothesis, while the human capital theory implies the family-to-work hypothesis. Recent empirical research suggests a moderating role of gender (Carlson and Lynch 2017); that is, the housework-earnings relationship differs between genders: while men display a unidirectional housework-to-earnings relationship, supporting the family-to-work hypothesis, women display a bidirectional housework-earnings relationship, supporting both the work-to-family hypothesis and the family-to-work hypothesis. This study examines the long-term relationship between housework time and market earnings among married individuals in urban China. These empirical tests enrich the debate between the family-to-work hypothesis and the work-to-family hypothesis. We reach the following conclusions.

First, the great differences between the results of the CLPM and the RI-CLPM in this study suggest the necessity to separate between-person differences from within-person processes when identifying the longitudinal housework-earnings relationship. The CLPM results show a reciprocal housework-earnings association, suggesting that, at the between-person level, market earnings were related to housework time and vice vasa. However, when adjusting for these stable between-person differences, these crosslagged associations largely disappeared, but autoregressive effects remained. Withinperson fluctuations in market earnings predict future changes in market earnings: significant within-person autoregressive paths indicate adults who exhibit increases in the typical levels of their market earnings at one measurement occasion are likely to experience increases in their market earnings at the next measurement occasion. This is only partly true for housework time: only starting from the beginning of 2006 do higher than typical levels of housework time imply within-person increases in housework time at 
the next measurement occasion. The autoregressive effects are much larger than the cross-lagged effects. Underlying these findings is the idea that each individual's housework time and market earnings depend on early life experiences. Prior theories shed light on this point. The human capital theory suggests that capital investment and accumulation are critical for increases in market returns. The gender perspective implies that housework performance is inseparable from cultural beliefs and gender attitudes developed in childhood and embedded in the whole society.

The only within-person cross-lagged housework-earnings relationship occurs in the period from 2004 to 2006 and applies only to women: women's higher than usual earnings in 2004 mean reductions in housework time in 2006. This finding partially supports the work-to-family hypothesis and provides no evidence for the family-to-work hypothesis. More specifically, when discussing the housework-earnings relationship among urban married Chinese individuals, human capital theory and the gender perspective are not entirely appropriate, given that individuals' housework time does not impact their market earnings (human capital theory), men's lower earnings do not imply less housework time (doing gender hypothesis), and women's higher earnings do not imply more housework time (gender neutralization hypothesis). Instead, the finding suggests that higher economic independence implies women's greater bargaining power within the family, which supports autonomy theory and the relative resources perspective. Further examinations show that from 2004 to 2006, men and women displayed fairly similar earning increases and housework decreases (mean difference ${ }_{\mathrm{HW}}=-0.51$, $t=-0.49$; mean difference $\mathrm{ME}=-2.19, t=-1.15$ ), but women's changes in housework time and market earnings had a much stronger correlation than men's (0.03 vs. -0.01$)$. Thus, the finding that women's higher than usual earnings in 2004 predicted decreased housework time in 2006 should not be too surprising. Given that the original model had adjusted for individual sociodemographic factors, job characteristics, family background, and regional characteristics, the mechanisms underlying this relationship need to be further examined.

There are a few potential explanations for our finding that few cross-lagged housework-earnings relationships exist at the within-person level. It could be that the traditional gender beliefs and the separate spheres model are persistent (as shown by the strong autoregression effects than the cross-lagged effects) to the extent that men's little housework time exerts no, if any, influence on their market earnings and women's nearly constant large share of housework fails to impact their market performance. Indeed, recent research fails to provide evidence for a converging trend of housework time between Chinese men and Chinese women that is commonly found in Western countries (Luo and Chui 2018). This nonconverging trend is because women currently still do the lion's share of housework and show only slight signs of decreasing their housework time and that men's housework decreases rather than increases, contrary to their Western counterparts. The persistent separate spheres model implies little changes within the family in the past 12 years, at least in terms of housework time. These minute changes can only have minimal effects on individuals' labor market performance.

Nonetheless, women's within-person, cross-lagged effect regarding the houseworkearnings associations disappears after 2006. This could be attributable to women's less advantageous position in the labor market after 2006. In the past decade, job 
characteristics have become increasingly more important in determining people's market performance (i.e., earnings) than human capital. However, women show minimal changes in the work sectors in the reform period. For instance, using event history analyses, Cao and $\mathrm{Hu}$ (2007) find that although educated men benefit most from market reform, married women are less likely to take advantage of opportunities in the emerging labor market; instead, women are more likely to experience family-oriented job changes and involuntary terminations, leading to a widened gender gap in job mobility. The widened gender gap in job mobility is intertwined with two processes: gendered role differentiation and increasing discrimination against women in the labor market. It could also be that during the 12-year investigation period, the gender gap in market earnings increases due to women's slower increases in market earnings than men's increases. The widening gap in market earnings signals women's laggard status in economic autonomy and bargaining power, which, according to autonomy theory and relative resources theory, can be used to exchange for less housework time.

The results also show that men's higher educational attainment is consistently associated with higher market earnings and more housework time, suggesting education's key role in accumulating human capital and in breaking the separate spheres model. Other factors, such as daily market work hours, show opposite effects: increases in one outcome variable (e.g., market earnings) and decreases in another (e.g., housework time). For women, education matters as well: a higher degree implies increases in earnings and decreases in housework time, a well-known finding established in previous research. Additionally, although women living in more developed regions (e.g., coastal areas) have more housework time, they also have higher market earnings.

This study has several limitations. First, we did not test whether each of the five theoretical perspectives on the housework-earnings relationship applies to Chinese individuals due to the research emphasis and for models' brevity. This study examines the housework-earning relationship by separating within-person processes from betweenperson processes (not within-couple processes from between-couple processes). Nonetheless, this study did test some of the theories. For instance, the current study examined whether in couples in which the wife had a higher level of (absolute) income, the wife's housework time decreased (autonomy theory), and whether more housework time inhibited the individual's market earnings (human capital theory). Our analytic models do not take spousal resources (e.g., spousal education and market earnings) into account. So we do not test whether in couples with relatively equal earnings, husbands and wives may have a more equitable sharing of housework (relative resources hypothesis) or whether in couples in which the wife earned more than the husband, the wife's hours of housework increased and the husband's decreased (doing gender perspective).

Second, while the RI-CLPM has comparable advantages in exploring longitudinal relationships between two variables, particularly when compared to the traditional CLPM, the RI-CLPM assumes that the between-person differences remain stable over time, which is a rather strong assumption. Third, prior research suggests that the development of gender attitudes might begin with early childhood experiences and has great influences on both market and domestic performance. This study could not explore the influence of gender attitude and only reports the longitudinal housework-earnings associations over a 12-year span. Fourth, although this study reveals that gender has different implications for the associations between market earnings and housework time, it 
does not offer clear answers on why there is only a cross-lagged effect of paid work on domestic work for women (and only in 2004 to 2006) but not for men. More nuanced research is needed in the future.

To conclude, overall, this study finds that the bidirectional housework-earnings relationship mainly occurred at the between-person level: higher market earnings were related to less housework time. For both men and women, within-person fluctuations in housework time at all times do not predict market earnings in the future. However, within-person fluctuations in market earnings predict future changes in market earnings. Only in 2004 and 2006 do women's within-person fluctuations in market earnings predict their housework time two years later: higher than anticipated market earnings in 2004 predict a lower than typical level of housework time in 2006, providing partial support for the work-to-family hypothesis.

\section{Abbreviations \\ CHNS: China Health and Nutrition Survey; CLPM: Cross-lagged panel model; RI-CLPM: Random intercept cross-lagged panel model}

\section{Acknowledgements}

The authors are grateful for comments from Dr. Clifton Emery, Dr. Vivian Lou, and Dr. Laiching Leung.

\section{Authors' contributions}

The first author did the analyses. The second author helped refine the conceptual framework. Both authors read and approved the final manuscript.

Funding

No funding is reported.

Availability of data and materials

The data can be found in CHNS's website: https://www.cpc.unc.edu/projects/china

\section{Competing interests}

The authors declare no competing interests.

\section{Author details}

${ }^{1}$ Department of Sociology, Zhejiang University, 866 Yuhangtang Road, Hangzhou, Zhejiang, China. ${ }^{2}$ Department of Social Work and Social Administration, The University of Hong Kong, Hong Kong, China.

Received: 10 October 2019 Accepted: 6 April 2020

Published online: 06 May 2020

\section{References}

Altonji, Joseph G., and Rebecca M. Blank. 1999. Race and gender in the labor market. In Handbook of labor economics, ed. O. Ashenfeher and D. Card, vol. 3, 3143-3259. Amsterdam: Elsevier B. V.

Becker, Gary S. 1985. Human capital, effort, and the sexual division of labor. Journal of Labor Economics 3 (1, Part 2): S33-S58.

Bian, Yanjie. 2002. Chinese social stratification and social mobility. Annual Review of Sociology 28 (1): 91-116.

Bian, Yanjie, and John R. Logan. 1996. Market transition and the persistence of power: The changing stratification system in urban China. American Sociological Review 61 (5): 739-758.

Bianchi, Suzanne M., and Melissa A. Milkie. 2010. Work and family research in the first decade of the 21st century. Journal of Marriage and Family 72 (3): 705-725.

Bianchi, Suzanne M., Melissa A. Milkie, Liana C. Sayer, and John P. Robinson. 2000. Is anyone doing the housework? Trends in the gender division of household labor. Social Forces 79 (1): 191-228.

Brines, J. 1994. Economic dependency, gender, and the division of labor at home. American Journal of Sociology 100 (3): $652-$ 688.

Cao, Yang, and Chiung-Yin Hu. 2007. Gender and job mobility in postsocialist China: A longitudinal study of job changes in six coastal cities. Social Forces 85 (4): 1535-1560.

Carlson, Daniel L., and Jamie L. Lynch. 2017. Purchases, penalties, and power: The relationship between earnings and housework. Journal of Marriage and Family 79 (1): 199-224.

Chen, Xi, and Suqin Ge. 2018. Social norms and female labor force participation in urban China. Journal of Comparative Economics 46 (4): 966-987.

Fahlén, Susanne. 2016. Equality at home-A question of career? Housework, norms, and policies in a European comparative perspective. Demographic Research 35 (48): 1411-1440.

Fan, Gang, Xiaolu Wang, and Guangrong Ma. 2011. Contribution of marketization to China's economic growth. Economic Research Journal 9 (283): 1997-2011.

Greenstein, Theodore N. 2000. Economic dependence, gender, and the division of labor in the home: A replication and extension. Journal of Marriage and Family 62 (2): 322-335. 
Gupta, Sanjiv. 2006. Her money, her time: Women's earnings and their housework hours. Social Science Research 35 (4): $975-$ 999.

Gupta, Sanjiv. 2007. Autonomy, dependence, or display? The relationship between married women's earnings and housework. Journal of Marriage and Family 69 (2): 399-417.

Gupta, Sanjiv, and Michael Ash. 2008. Whose money, whose time? A nonparametric approach to modeling time spent on housework in the United States. Feminist Economics 14 (1): 93-120.

Gustafsson, Björn, and Shi Li. 2000. Economic transformation and the gender earnings gap in urban China. Journal of Population Economics 13 (2): 305-329.

Hamaker, Ellen L., Rebecca M. Kuiper, and Raoul P. Grasman. 2015. A critique of the cross-lagged panel model. Psychological Methods 20 (1): 102-116

He, Guangye. and Wu, Xiaogang. 2018. Dynamics of the gender earnings inequality in reform-era urban China. Work, Employment and Society 32(4):726-746.

Hook, Jennifer L. 2010. Gender inequality in the welfare state: Sex segregation in housework, 1965-2003. American Journal of Sociology 115 (5): 1480-1523.

Hook, Jennifer L. 2017. Women's housework: New tests of time and money. Journal of Marriage and Family 79 (1): 179-198.

Hu, Li-tze, and Peter M. Bentler. 1999. Cutoff criteria for fit indexes in covariance structure analysis: Conventional criteria versus new alternatives. Structural Equation Modeling: A Multidisciplinary Journal 6 (1): 1-55.

Ji, Yingchun, Xiaogang Wu, Shengwei Sun, and Guangye He. 2017. Unequal care, unequal work: Toward a more comprehensive understanding of gender inequality in post-reform urban China. Sex Roles 77 (11-12): 765-778.

Lachance-Grzela, Mylène, and Geneviève Bouchard. 2010. Why do women do the lion's share of housework? A decade of research. Sex Roles 63 (11-12): 767-780.

Liu, Jieyu. 2007. Gender dynamics and redundancy in urban China. Feminist Economics 13 (3-4): 125-158.

Luo, Meng Sha. 2019. Gender division of labor in China: Changes in domestic work and market work in the early $21 \mathrm{st}$ century (Doctoral dissertation, The University of Hong Kong, Hong Kong, China). Retrieved from https://books.google. com/books?id=EDUFywEACAAJ (Retrieved on 2020/3/26).

Luo, Meng Sha, and Ernest Chui. 2018. Gender division of household labor in China: Cohort analysis in life course patterns. Journal of Family Issues 39 (12): 3153-3176.

Luo, Meng Sha, and Ernest Chui. 2019. Moving from rural to urban China: How urbanization affects women's housework. Sex Roles 81 (3): 127-139.

Mund, Marcus, and Nestler, Steffen. 2018. Beyond the cross-lagged panel model: Next-generation statistical tools for analyzing interdependencies across the life course. Advances in Life Course Research: Online first.

Muthén, L.K., and B.O. Muthén. 1998-2017. Mplus User's Guide. Los Angeles, CA: Muthén \& Muthén.

National Bureau of Statistics. (2004). Women and Men in China: Facts and Figures 2004. Retrieved from http://en.wsic.ac.cn/ staticdata/248.htm ()

National Bureau of Statistics. (2012). Women and Men in China: Facts and Figures 2012. Retrieved from http://www.unicef.cn/ en/uploadfile/2014/0109/20140109030938887.pdf ()

Pimentel, Ellen Efron. 2006. Gender ideology, household behavior, and backlash in urban China. Journal of Family Issues 27 (3): $341-365$.

Pinto, Katy M., and Scott Coltrane. 2009. Divisions of labor in Mexican origin and Anglo families: Structure and culture. Sex Roles 60 (7): 482-495.

Sayer, Liana C. 2005. Gender, time and inequality: Trends in women's and men's paid work, unpaid work and free time. Social Forces 84 (1): 285-303.

Shelton, Beth Anne, and Daphne John. 1996. The division of household labor. Annual Review of Sociology 22 (1): $299-322$.

Sullivan, Oriel. 2011. An end to gender display through the performance of housework? A review and reassessment of the quantitative literature using insights from the qualitative literature. Journal of Family Theory \& Review 3 (1): 1-13.

Tang, Wenfang, and William L. Parish. 2000. Chinese Urban Life under Reform: The Changing Social Contract. Cambridge: Cambridge University Press.

Wang, Xiaolu, Gang Fan, and Jingwen Yu. 2017. Marketization Index of China's Provinces: NERI Report 2016. Beijing, China: Social Sciences Academic Press.

Wang, Zheng. 2003. Gender, employment and women's resistance. In Chinese Society: Change, Conflict and Resistance, ed. E.J. Perry and M. Selden. New York, NY: Routledge.

Wu, Xiaogang, Peng Wang, and Chao Huang. 2016. Family patronage, institutional patronage, and work family conflict: women's employment status and subjective well-being in urban China. The Journal of Chinese Sociology 3 (1): 21.

Wu, Yuxiao, and Xiaogang Wu. 2009. Occupational gender segregation and gender wage gap in urban China. Sociological Studies 4: 88-111.

Yu, Jia, and Yu. Xie. 2018. Motherhood penalties and living arrangements in China. Journal of Marriage and Family 80 (5): $1067-1086$.

Zhang, Yuping, and Emily Hannum. 2015. Diverging fortunes: The evolution of gender wage gaps for singles, couples, and parents in China, 1989-2009. Chinese Journal of Sociology 1 (1): 15-55.

Zhang, Yuping, Emily Hannum, and Meiyan Wang. 2008. Gender-based employment and income differences in urban China: Considering the contributions of marriage and parenthood. Social Forces 86 (4): 1529-1560.

Zuo, Jiping. 2003. From revolutionary comrades to gendered partners: Marital construction of breadwinning in post-Mao urban China. Journal of Family Issues 24 (3): 314-337.

Zuo, Jiping. 2014. Understanding urban women's domestic-role orientation in post-Mao China. Critical Sociology 40 (1): $111-$ 133.

Zuo, Jiping, and Yanjie Bian. 2001. Gendered resources, division of housework, and perceived fairness_A case in urban China. Journal of Marriage and Family 63 (4): 1122-1133.

\section{Publisher's Note}

Springer Nature remains neutral with regard to jurisdictional claims in published maps and institutional affiliations. 